\title{
Correction: Ocular surface indicators and biomarkers in chronic ocular graft-versus-host disease: a prospective cohort study
}

Alexandra A. Pietraszkiewicz (D) Debbie Payne - Maria Abraham - Angel Garced - Krishna C. Devarasetty Megan Wall - Supriya M. Menezes · Sveti Ugarte - Filip PirsI (1) - Sencer Goklemez • Frederick L. Ferris • John Barrett - Minoo Battiwalla $\cdot$ Richard W. Childs $\cdot$ Steven Z. Pavletic $\cdot$ Rachel J. Bishop

Published online: 10 May 2021

(c) The Author(s), under exclusive licence to Springer Nature Limited 2021

Correction to: Bone Marrow Transplantation https://doi.org/10.1038/s41409-021-01254-5

Due to a processing error the presentation of Table 1 was incorrect. The correct table is given below.
The new heading on page 2 right column of the article should read: "Clinical examination and sample collection". The original article has been corrected. 
Table 1 Baseline characteristics of patients and controls.

\begin{tabular}{|c|c|c|c|}
\hline & Characteristic & $\begin{array}{l}\text { Intended HSCT } \\
\text { cohort }(n=40)^{\mathrm{a}}\end{array}$ & $\begin{array}{l}\text { Controls } \\
(n=20)^{\mathrm{a}}\end{array}$ \\
\hline \multirow[t]{2}{*}{ Age } & Median (range) & $40.5(20-70)$ & $\begin{array}{l}38.5 \\
(21-73)\end{array}$ \\
\hline & Mean & 41.3 & 39.3 \\
\hline \multirow[t]{2}{*}{ Sex } & Male & $21(52.5 \%)$ & $\begin{array}{l}9 / 20 \\
(45.0 \%)\end{array}$ \\
\hline & Female & $19(47.5 \%)$ & $\begin{array}{l}11 / 20 \\
(55.0 \%)\end{array}$ \\
\hline \multirow{14}{*}{$\begin{array}{l}\text { Primary } \\
\text { diagnosis }\end{array}$} & AA & $8(20 \%)$ & \\
\hline & ALL & $9(22.5 \%)$ & \\
\hline & AML & $7(17.5 \%)$ & \\
\hline & APL & $1(2.5 \%)$ & \\
\hline & CGD & $1(2.5 \%)$ & \\
\hline & CLL & $1(2.5 \%)$ & \\
\hline & $\begin{array}{l}\text { Cutaneous } \\
\text { Lymphoma }\end{array}$ & $1(2.5 \%)$ & \\
\hline & $\begin{array}{l}\text { Follicular } \\
\text { Lymphoma }\end{array}$ & $1(2.5 \%)$ & \\
\hline & $\mathrm{HL}$ & $1(2.5 \%)$ & \\
\hline & $\begin{array}{l}\text { Mantle Cell } \\
\text { Lymphoma }\end{array}$ & $1(2.5 \%)$ & \\
\hline & MDS & $4(10.0 \%)$ & \\
\hline & $\mathrm{MM}$ & $1(2.5 \%)$ & \\
\hline & $\begin{array}{l}\text { Plasmocytic } \\
\text { dendritic cell } \\
\text { neoplasm }\end{array}$ & $1(2.5 \%)$ & \\
\hline & SCA & $3(7.5 \%)$ & \\
\hline \multirow{2}{*}{$\begin{array}{l}\text { Type of } \\
\text { transplant }(n= \\
36)^{\mathrm{b}}\end{array}$} & HLA matched & $32(88.8 \%)$ & \\
\hline & Unmatched & $4(11.1 \%)$ & \\
\hline \multirow{4}{*}{$\begin{array}{l}\text { Total Body } \\
\text { Irradiation }\end{array}$} & Yes & $25(69.4 \%)$ & \\
\hline & $\begin{array}{l}\text { Low-dose } \\
(<600 \mathrm{~Gy})\end{array}$ & $6 / 25(24.0 \%)$ & \\
\hline & $\begin{array}{l}\text { High-dose } \\
(\geq 600 \text { Gy) }\end{array}$ & $19 / 25(76.0 \%)$ & \\
\hline & No & $11(30.5 \%)$ & \\
\hline \multirow{2}{*}{$\begin{array}{l}\text { Conditioning } \\
\text { regimen }\end{array}$} & Myeloablative & $20(55.5 \%)$ & \\
\hline & $\begin{array}{l}\text { Non- } \\
\text { Myeloablative }\end{array}$ & $16(44.4 \%)$ & \\
\hline \multirow[t]{2}{*}{$\begin{array}{l}\text { Stem } \\
\text { cell source }\end{array}$} & $\begin{array}{l}\text { Cord blood and } \\
\text { peripheral blood }\end{array}$ & $4(11.1 \%)$ & \\
\hline & Peripheral blood & $32(88.8 \%)$ & \\
\hline
\end{tabular}

${ }^{\mathrm{a}} \mathrm{N}$ corresponds to the number of participants.

${ }^{\mathrm{b}}$ Four patients did not receive an HSCT.

$H S C T$ hematopoietic stem cell transplant, $A A$ aplastic anemia, $A L L$ acute lymphoblastic leukemia, $A M L$ acute myeloid leukemia, $A P L$ acute promyelocytic anemia, $C G D$ chronic granulomatous disease, $C L L$ chronic lymphoblastic leukemia, $H L$ hodgkin lymphoma, $M D S$ myelodysplastic syndrome, $M M$ multiple myeloma, $S C A$ sickle cell anemia, HLA human leukocyte antigen, Gy gray 